\title{
Interpretation of Symbolism in Willa.Cather novel "A Lost Lady"
}

\author{
Qiaohong ZHAO \\ Luohe Medical College \\ Luohe,462000 China
}

\begin{abstract}
A Lost Lady" is at beginning of the 20th century, a important work of creation of a famous American writer Willa Cather, through a story that a woman in a social swirl in old age gradually fall and sink, it reflects the commercialization of human society and other traditional values and lifestyle impact and erosion, and the desire of mankind for a better civilization. Works use artistic symbolism to play a certain role in the development of the plot, the characters change shape and opposition figures to portray the psychological state.
\end{abstract}

Keywords- Willa Cather; symbolism; mental state

\section{INTRODUCTION}

"A Lost Lady," the novel was published in 1923, and the works is in the famous American stage - Willa Cather woman writer (1873-1947) writing career, there are scholars who attributed the tragedy during this stage, because the Kaiser speaking "to the 1922 World fission occurred entirely and no longer has integrity, but into two or three different combinations of body," works of this period reflect the author's commercial and cultural impact people's mental transformation of anxiety and anger, the erosion of the old way of life, the loss of traditional values decay feelings, as well as the love and lament for good times gone.

Primarily through the novel in a Brinton old railway town - Sweetwater - Herbert Neil grew up in fragmented memories, through what is seen and heard by people lived in the late 'pioneering era ", elegant and charming and the final destruction of the Marianne - Forrest image and decades of experience of a Lady Captain Forrest is presented to readers. Marian's husband Captain Forrest, as "conquered the mountain with iron wheel wagon western plains," the older generation of pioneers, was also a pioneer in the construction of the railway, the body retains generous, kind-hearted virtue, "broad-minded" "excludes the real benefits," but in a capitalist revolution commercialized society, they are growing old, "it is not proficient in setting" and eventually dies. And he was 25 years younger than the wife of a Marian, it should belong to the era of the Wild (Bijing is Captain Forrest achievements she Sweetwater lady's identity and status), but she not willing to live and die with the old times. After her husband's death, she "sit back and enjoy" and "never take risks," but now she mixed together with who called "new era" master Ivy - Peters, and then was abandoned and homesteads occupied, she marred wealthy
Englishman, and ultimately died in foreign country. She just groan off old age in the social swirl surging development, the novel tells the story of the sink, and more importantly, the pioneering era in the history of the wheels continue to move forward in the passage, for the commercialization of the social context of historical change to replace of human desire and spiritual inquiry.

"A Lost Lady," this novella, has no bizarre plot twists, flowery descriptions, burdensome intricate details, but the author strokes with fresh, clever narrative techniques, simple and succinct text, bringing readers light aftertaste and spiritual beauty of deep thinking and explore. Many works appeared in symbolism, the development of the plot, characters opposition figure shaping and mental status changes and novels portray the theme have played a prominent role in promoting and it is not ignored.

\section{SYMBOLISM IN THE WORKS}

The boys began to describe a group of novels including Neil - Herbert including Mrs. Forrest who has been allowed in the picnic grove, and she suffered that cruelly Ivy • Peters left the scene to go to the bird eyes, as people peeing endless: Introduction the purpose of the birds in the air, struggling to hit left to eat right, disoriented and painful spin. People about the awakened from idyllic tranquil scene, often hide or are behind surging violence in the good things, the ugly undercurrent. Bird is female, and the author is so subtle arrangements profound implication. Introduction of birds' eye imagery, with the development of the plot, means increasingly clear image to become a symbol of the portrayal that Mrs. Forrest later by beautiful and elegant lady gradually reduced to others who are abandoned mistress and rough tragic fate. The Ivey - Herbert Peters and Neil, two people injured save the different attitude towards the question of the relationship between the main characters, it provides hints symbolic, but also foreshadowed the characters shaped and future development of the plot.

Ivy Peters, nicknamed "Poison Ivy", "poison" means poison, Ivy (Ivy) is with ivy (ivy) homonyms, ivy is a highly cling plants. His sinister, vicious nature can peep evident from his nickname. He will be left to the birds and move its eyes in the captain's death, Mrs. Forrest plays on top of the hands after he marries someone else, and the Forrester family property themselves, sit back and enjoy the despicable acts exactly the same, but also the future fate of Mrs. Forrest was 
foreshadowing. - Neil Herbert places a kind of positive image, for the birds and climbing relief from pain, it gets taken care of Mrs. Forrest fell faint from the beginning, which is regarded as the eyes of the goddess and 'she had a sort of something, you will be able to flash it; you will be keen to notice her, notice her fragility and elegance ....... "With the development of the story, the reader is not difficult to understand the future of his wife for the maintenance of Forrest in his mind the image of an elegant lady, it has shown compassion, attitude and behavior to protect and help: When Neil found Captain Forrest letter asking him to send on behalf of Mrs. Forrest in a letter to his lover, even despised in her behavior, he still immediately wanted to hide her disguise; Again, in the newspapers there ambiguous relationship with her married Frank - Ai Linge news, Neil thought was sad to visit and comfort Mrs. Forrest; when Mrs. Forrest dangerous disregard of flooding caused by heavy rains came from Neil place to call their rap lover, when she is almost out of control of emotions, Neil cut the telephone connection, it is not only to protect her reputation, but also to maintain her in the eyes of Forrest Captain white to have respectable expensive Mrs. image. In addition, at the cause of the failure of Captain Forrest, deteriorating health, she could not afford to take care of their financial situation and attracted the rumors when they are suspended for one year to act as a protective Neil's role, who help them maintain their image Neil, as the descendants of the pioneers of the faithful, it is the story of the witness, who reviewed many events, Cather with Neil objective perspective show changes in the plot, the character's personality and image, and his moral judgment is on behalf of the Kaiser merits, it inherited the responsibility of the traditional culture of virtue.

Similarly, roses are commonly used to convey affection, but also in order to become Kaiser convey emotion, they are psychological changes characterization tools. With contact with Mrs. Forrest increasing, Neil told her (Neil mind distinguished goddess) admiration deeper feelings. When he picked up some wild roses and ready give Forrest wife, when they found her lover Frank - Ai Linge and fool around, he felt very indignant, and then rose fell in the mud.

This move is not out of Mrs. Forrest for his persistent acts of moral feeling hurt, it is more precisely that Neil idealized view of Mrs. Forrest from the foundation shaken: "elegant demeanor, sweet colorful voice, dark eyes laughing and fantasy glory all became dirt. She was not a moral scruples ruined, but a beauty ideal. "In fact, Neil to her admiration and her beautiful image in his mind is based on the Forrest wife for her husband's loyalty. Her show noble and charming is the source of Bai Furui Captain Lancaster shelter, and it is the pioneering era of the Wild

Those who have the virtue of persistence exudes brilliance make it glow. Thus, to be thrown away roses symbolize love and this beautiful image of subversion and disillusionment.

The second part of the second chapter of the novel Forrest Captain's Day show to watch Neil lip, it also has a symbolic meaning implied. As the ancient shadows cast by the sun when asked to identify the instrument, the first is a symbol of the past; and it is positive, Captain Forrest career suffered the blow of failure (White has large investment bank failures, White has been funded payments and to protect the interests of depositors), it is also suffering from a stroke. The sun slowly rotates projection, and silent passage indicates that Captain Forrest barely had much time, life countdown inexorably toward old age and death. When he died, he was placed on the tomb lip date, and it is not just a pioneer of old age and the end of its life, it is witness, a symbol of eternal stagnation and asked, a symbol of the pioneering era gone forever.

In addition, the background of the novel is concentrated on an ancient frontier town, and itself has a certain symbolic significance. Materialistic is filled with the stench of the business community on the frontier town of leisurely proper occlusion but idyllic life continue to impact and erosion brought about by the change from a certain reflection of the collision of old and new alternate, culture and people thought, and change of moral values.

In the novel, Forrest family's Everglades (marsh) is not only the material in the lake's aquatic dense debris deposition zone, but it has become a symbol of the pioneering era of culture, tradition and white by lifestyle, so when a new generation becomes bourgeois social forces around the town, the authors express such indignation: "They (explorers, pioneers) have reclaimed large tracts of land fell like Ivey $\bullet$ Peters hands such people, two of them enjoy visions of others, to disperse the fresh morning air, shovel out the spirit of the great white thinking by repealing the great land occupied by white people in white lifestyle. In the large open soil, these colors, a pioneer of such unfettered earth style has been destroyed, it split into a profitable piece of a small piece ... as they like Ivey - Like Peters, only the Forrest family the swamp water pumping cleaners. "Forrest captain represented the older generation," not only conquered Changzhi, "while Ivey such as" smart young men "took the credit, mercenary. Marshlands in their eyes seems to be the untapped source of revenue and later Ivey - Peters drained the marshes in the water, it becomes profitable crop, Neil went to see the spirit of the Wild West, it is also a symbol of the transition era and forces changes in different cultures.

\section{CONCLUSION}

Some scholars believe that "A Lost Lady" is an important work of Cather's life writing, is her "old order of life clearest exposition" and is a summary of the past era that desirable "of that era. "Her traditional human spiritual pioneer frontier nostalgia and praise and depict, makes it "continues to materialistic civilization in a spirit of America's defenders."

US experts Cather Professor Brown said in the works, "Willa Cather • Critical Biography" in her novel "is a model of symbolism," it should be induced into profound symbolism art heuristic. "" a Lost Lady, "was" her to write the kind of novel deliberately 'unfurnished' "that is set aside Balzac style lengthy description of the objective environment, highlighting the image and meaning to a long the contents concentrated in a novella length.

Cather use sophisticated writing skills, the idea of sophisticated imagery and other symbolism give vivid works of artistic appeal, it played deep moral effect, and is easy to 
cause the association. A profound understanding of the works of exquisite uses symbolism, and will lead the reader in-depth understanding of the subject of the novel, cultural implication and profound practical significance.

\section{References}

[1] B Perkins Women's Work:. An Anthology of American Literatu re [M] 'The United States:. McGram-Hill, lnc .. 1994.

[2] Maxwell Geismar last batch of local writers [M]. New York: Macmillan Publishing Company .1950

[3] EK Brow n.Willa Lather: A Critical Biography [M] .N ewYork: AA Knorf lnc, 1953..

[4] Dong Hengyi. A Lost Lady - translation preface[M] Guilin: Lijiang Publishing House .1986.
[5] Middleton, Joann.Willa Lather 's M odernism: A Studv of Stvle and Technique [M] .FDU Press 1990..

[6] Karen J Warren.Feminism and Ecology [J] .Environmental Re-view, 1987: 3 .

[7] Zhu Jiongqiang. Willa Cather selection - Set [M] Beijing: Yanshan Press, 2004.

[8] Luo Ting. Feminist literary criticism in the unitary side and China[M]. Beijing: China Social Sciences Press, 2004.

[9] James Schroeter.Willa Cather and Her Critics [M] .Cornell University Press, 1967. 